\title{
Synthesis and 3D Interconnected Nanostructured h-BN-Based Biocomposites by Low-Temperature Plasma Sintering: Bone Regeneration Applications
}

Chandkiram Gautam, ${ }^{*}, \dagger$, Dibyendu Chakravarty, ${ }^{\S, \propto}$ Amarendra Gautam, ${ }^{\ddagger}$ Chandra Sekhar Tiwary, ${ }^{\dagger, \propto}$ Cristiano Francisco Woellner, ${ }^{\dagger, \perp}$ Vijay Kumar Mishra, " Naseer Ahmad," Sehmus Ozden, ${ }^{\dagger}$ Sujin Jose, ${ }^{\prime}$ Santoshkumar Biradar, ${ }^{\dagger}$ Robert Vajtai, ${ }^{\dagger}{ }^{\circ}$ Ritu Trivedi, ${ }^{\|}$Douglas S. Galvao, ${ }^{\perp}$ a and Pulickel M. Ajayan ${ }^{\dagger}$

${ }^{\dagger}$ Department of Materials Science and Nano Engineering, Rice University, Houston, Texas 77005, United States

${ }^{\ddagger}$ Department of Physics, University of Lucknow, Lucknow, Uttar Pradesh 226007, India

${ }^{\S}$ International Advanced Research Center for Powder Metallurgy and New Materials (ARCI), Balapur, P. O., Hyderabad, Telangana 500005, India

"Endocrinology Division, CSIR-Central Drug Research Institute, Lucknow, Uttar Pradesh 226031, India

${ }^{\perp}$ Applied Physics Department, State University of Campinas-UNICAMP Campinas, São Paulo 13083-859, Brazil

${ }^{\#}$ School of Physics, Madurai Kamaraj University, Madurai, Tamil Nadu 625021, India

Supporting Information

ABSTRACT: Recent advances and demands in biomedical applications drive a large amount of research to synthesize easily scalable low-density, high-strength, and wearresistant biomaterials. The chemical inertness with low density combined with high strength makes h-BN one of the promising materials for such application. In this work, three-dimensional hexagonal boron nitride (h-BN) interconnected with boron trioxide $\left(\mathrm{B}_{2} \mathrm{O}_{3}\right)$ was prepared by easily scalable and energy efficient spark plasma sintering (SPS) process. The composite structure shows significant densification $\left(1.6-1.9 \mathrm{~g} / \mathrm{cm}^{3}\right)$ and high surface area $\left(0.97-14.5 \mathrm{~m}^{2} / \mathrm{g}\right)$ at an extremely low SPS temperature of $250{ }^{\circ} \mathrm{C}$. A high compressive strength of $291 \mathrm{MPa}$ with a reasonably good wear resistance was obtained for the composite structure. The formation of strong covalent bonds between h-BN and $\mathrm{B}_{2} \mathrm{O}_{3}$ was formulated and established by molecular dynamics simulation. The composite showed significant effect on cell viability/proliferation. It shows a high mineralized nodule formation over the control, which suggests its use as a possible osteogenic agent in bone formation.

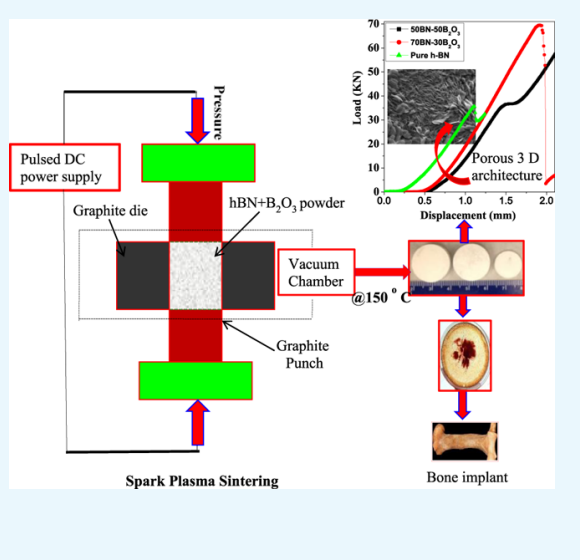

\section{INTRODUCTION}

Analogous to graphene, hexagonal boron nitride (h-BN) possesses high oxidation resistance and chemical stability, along with high surface area and thermal conductivity. ${ }^{1-4}$ Therefore, developing nanostructured three-dimensional (3D) $\mathrm{h}-\mathrm{BN}$ is expected to increase its significance in applications. ${ }^{5-7}$ Various routes (chemical, mechanical, chemical vapor deposition (CVD), and microwave irradiation) are employed for synthesizing porous nanostructured BN-based materials. ${ }^{8-11}$ It is extensively prepared by reaction of boric acid, $\mathrm{B}_{2} \mathrm{O}_{3}$ or borax with $\mathrm{C}$ and $\mathrm{N} / \mathrm{NH}_{3}$ and urea at high temperatures around 2000 ${ }^{\circ} \mathrm{C}$. For nanostructured $\mathrm{BN}$, laser ablation, $\mathrm{CVS}$, and carbothermal reduction of $\mathrm{B}_{4} \mathrm{C}$ and $\mathrm{B}_{2} \mathrm{O}_{3}$ are reported. ${ }^{12} \mathrm{~A}$ transient $\mathrm{BO}$-based liquid phase helps densification at $<1000$ ${ }^{\circ} \mathrm{C}$, although the h-BN and the matrix phases develop at $\sim 1600$ ${ }^{\circ} \mathrm{C}$ depending on the low free energy of formation of h-BN. ${ }^{13}$ The low melting point of $\mathrm{B}_{2} \mathrm{O}_{3}\left(450{ }^{\circ} \mathrm{C}\right)$ and low viscosity of melts of $\mathrm{B}_{2} \mathrm{O}_{3}$ help low-temperature consolidation of these compositions. For instance, a one-step synthesis of porous template-free $\mathrm{BN}$ microsponges for hydrogen storage applica- tion $^{14}$ and a template-assisted continuous 3D network of $\mathrm{BN}$ aerogels having borazine precursor for oil/organic solvent absorption were proposed recently. ${ }^{15}$ However, compared to graphene, the synthesizing routes for few-layered BN nanosheets are less effective due to the strong lip-lip interactions between the adjacent concentric shells of BN basal planes. ${ }^{16-18}$ The mechanical cleavage method for preparing h-BN is not suitable for scale up. ${ }^{19}$

Various forms of $3 \mathrm{D}$ porous nanostructured materials have been developed by different synthesis methods: bottom-up approaches like solution processing and chemical vapor deposition (CVD) and microwave irradiation. However, these processes yield products having lower modulus $(<10 \mathrm{MPa})$ and mechanical strength values. Spark plasma sintering (SPS) technique allows densification of various ceramic powders at lower temperature and shorter dwell time due to rapid heating

Received: April 12, 2018

Accepted: May 22, 2018

Published: June 4, 2018 

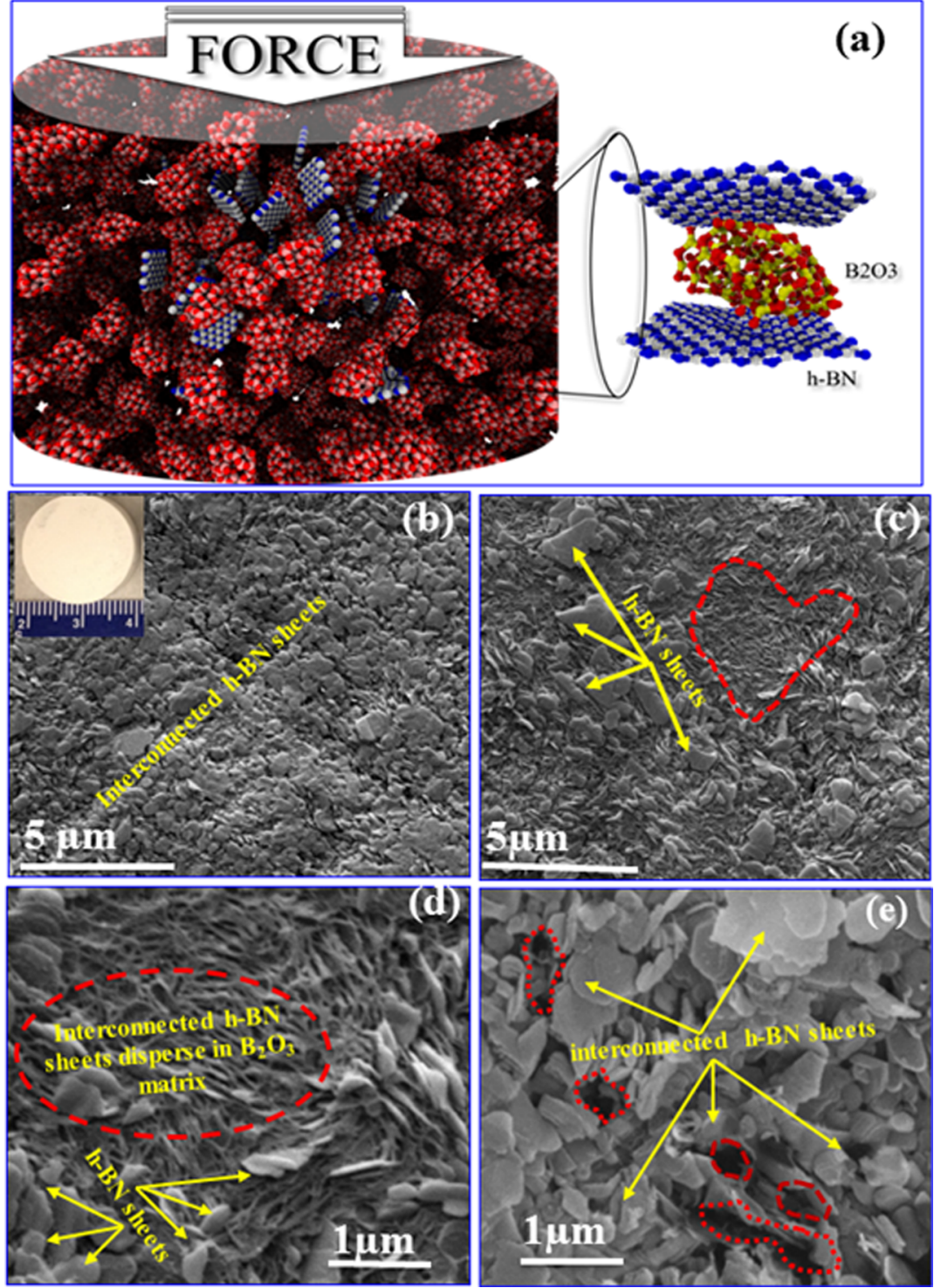

Figure 1. Surface morphology of SPS-sintered $\mathrm{BN}-\mathrm{B}_{2} \mathrm{O}_{3}$ composites. (a) Schematic of the proposed composite structure. (b) Scanning electron microscope (SEM) image of pure h-BN showing the tiny interconnected sheets of h-BN. (c, d) Low and high-magnification SEM images of sample $\mathrm{BN}-\mathrm{B}_{2} \mathrm{O}_{3}$ (BNBO) showing interconnected big h-BN sheets within the residual matrix of $\mathrm{B}_{2} \mathrm{O}_{3}$ and indicating the fibrous morphology of $\mathrm{B}_{2} \mathrm{O}_{3}$. (e) SEM image of high concentration h-BN sample shows fully developed and well interconnected nanosheets of h-BN with minor porosity dispersed in glassy matrix of $\mathrm{B}_{2} \mathrm{O}_{3}$.

and cooling rates. The controlled grain growth in this process leads to desired material properties. ${ }^{20}$ Recently, Chakravarty et. al. reported $3 \mathrm{D}$ porous graphene by SPS as the implants. They achieved significant mechanical strength of $40 \pm 3 \mathrm{MPa}$, stiffness of $8 \pm 1 \mathrm{kN} / \mathrm{m}$, and Young's modulus of $4.1 \pm 0.5$ $\mathrm{GPa}^{21}$ More recently, Gautam et. al. reported a detailed investigation on synthesis of porous h-BN 3D architecture for effective humidity and gas sensor applications using $\mathrm{B}_{2} \mathrm{O}_{3}$ as an additive, which is responsible for the porous structure. ${ }^{22}$

In the present work, attempts have been made to synthesize $3 \mathrm{D} h \mathrm{hBN}-\mathrm{B}_{2} \mathrm{O}_{3}$ composite using the SPS technique. The synthesized $3 \mathrm{D}$ structures are demonstrated to be structurally stable, mechanically strong, and biologically viable and sufficiently biocompatible to be used as bone implant. The $\mathrm{MD}$ simulation has been performed to understand the role of $\mathrm{B}_{2} \mathrm{O}_{3}$ in interconnecting h-BN to build the $3 \mathrm{D}$ structure and its effect on mechanical properties.

\section{RESULTS AND DISCUSSION}

2.1. Route, Sample Nomenclature, and Mechanism. A typical structure having differently oriented h-BN sheets intercalated by the second-phase $\mathrm{B}_{2} \mathrm{O}_{3}$ particles and forming strong covalent bonds under application of current and pressure in SPS has been proposed, as shown in the schematic Figure 1a. The nomenclature $x \mathrm{BNBO}$ was used for the samples synthesized in the current work, where " $x$ " stands for the weight percent of h-BN. This obviously implies that the $\mathrm{B}_{2} \mathrm{O}_{3}$ percentage for that sample is $(100-x)$.

2.2. Morphology Evolution. The influence of $\mathrm{B}_{2} \mathrm{O}_{3}$ concentration on grain growth, morphology, and general microstructure of $\mathrm{BNBO}$ composites was microscopically analyzed. Figure $1 \mathrm{~b}$ shows a typical SEM image of pure h-BN consisting of tiny sheets sintered to each other. The digital image of the sample sintered at $250{ }^{\circ} \mathrm{C}$ is shown in the inset. A SEM image of a typical $\mathrm{BNBO}$ sample reveals large 

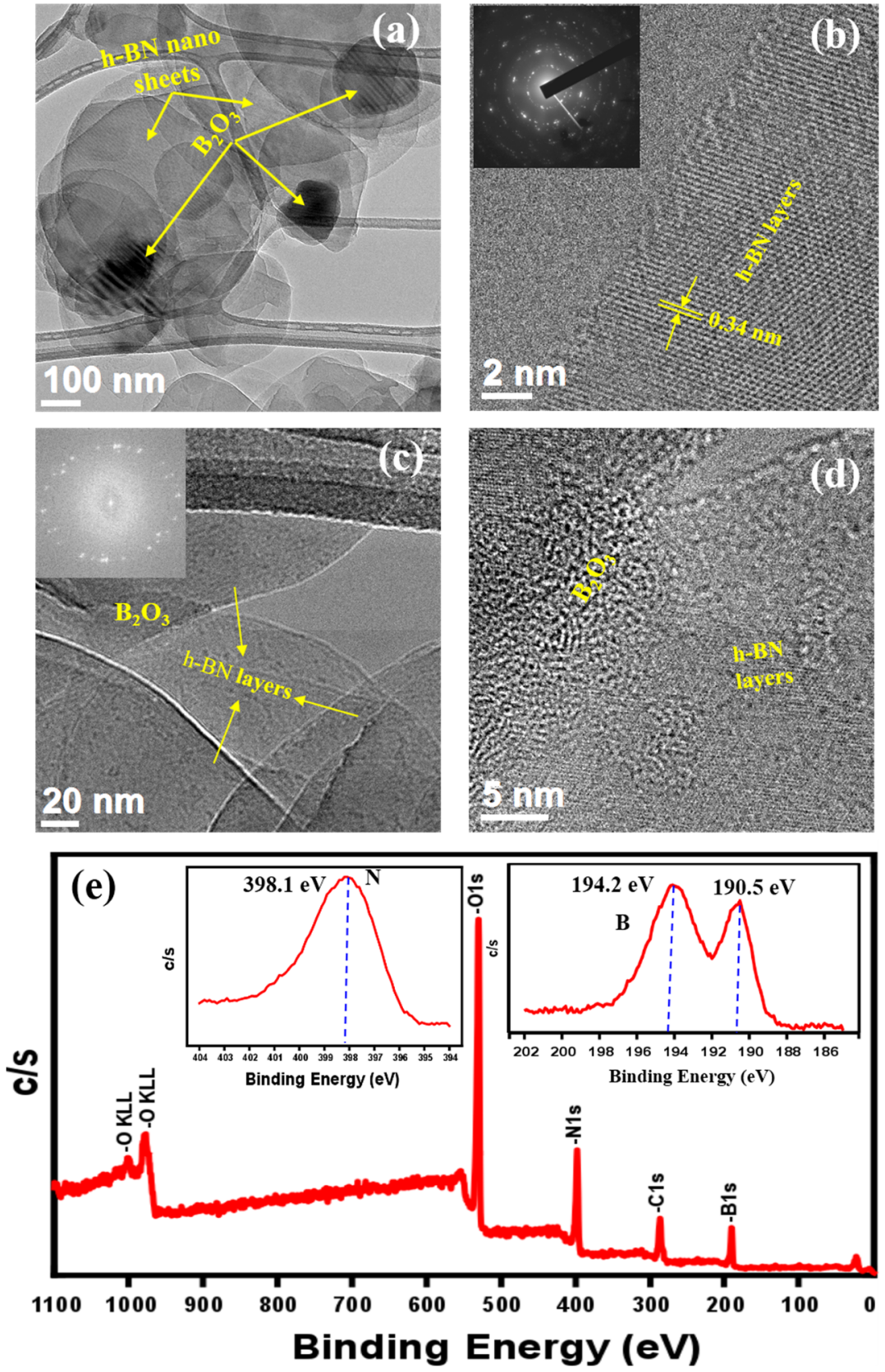

Figure 2. Microstructural characterization $\mathrm{BNBO}$ (a) low magnification bright field TEM image showing large h-BN sheets along with matrix of $\mathrm{B}_{2} \mathrm{O}_{3}$, (b) TEM image of synthesized $\mathrm{BN}-\mathrm{B}_{2} \mathrm{O}_{3}$ composites showing h-BN nanosheets; resulting in geometrically defined edges of both h-BN and $\mathrm{B}_{2} \mathrm{O}_{3}$ and inset showing the selected area electron diffraction (SAED) pattern having hexagonal crystalline patterns of h-BN, (c) high-magnification image at the edge of the sheet showing the number of layers of h-BN across to the (002) plane and also the interconnectivity of these sheets, (d) high-resolution TEM image showing hexagonal lattice of synthesized $\mathrm{BN}-\mathrm{B}_{2} \mathrm{O}_{3}$ composites, and (e) X-ray photoelectron spectroscopy (XPS) represents the chemical states of B and $\mathrm{N}$ elements and insets show the typical B $1 \mathrm{~s}$ and $\mathrm{N} 1 \mathrm{~s}$ spectra with corresponding binding energies of 194.21 and $398.4 \mathrm{eV}$, respectively.

interconnected h-BN sheets (marked by arrow in Figure 1c). The high-magnification image (Figure 1d) clearly reveals the $3 \mathrm{D}$ porous, interconnected architecture of the $\mathrm{hBN}-\mathrm{B}_{2} \mathrm{O}_{3}$ composite with the fibrous morphology of $\mathrm{B}_{2} \mathrm{O}_{3}$, as indicated by the dotted region. The high-magnification SEM micrograph shown in Figure 1e, corresponds to a high concentration h-BN sample and shows interconnected submicron $(\sim 0.4 \mu \mathrm{m}) \mathrm{h}-\mathrm{BN}$ sheets, represented by arrows, with large pores at a few regions created by partial evaporation of $\mathrm{B}_{2} \mathrm{O}_{3}$ during sintering. It is well known that $\mathrm{B}_{2} \mathrm{O}_{3}$ forms liquid phase during sintering; this might explain the high densification rate in the samples even at an extremely low SPS temperature. Formation of liquid phase may also promote orientation of the $\mathrm{h}-\mathrm{BN}$ grains by processes such as grain boundary rotation. ${ }^{23}$

The transmission electron microscopy (TEM) images, as shown in Figure $2 \mathrm{a}-\mathrm{d}$, correspond to those for the composition $90 \mathrm{BNBO}$ and are consistent with the observations made in the SEM images. The general macrostructure of the $\mathrm{B}_{2} \mathrm{O}_{3}$ particles dispersed in the h-BN nanosheets is shown in Figure 2a. The hBN sheets appear to be of $100-250 \mathrm{~nm}$ in diameter. The highresolution transmission electron microscopy image in Figure $2 \mathrm{~b}$ reveals a layered h-BN structure with an interlayer distance of 
$0.34 \mathrm{~nm}$ corresponding to the inter-plane distance (002), in agreement with a previous report. ${ }^{24}$ This image also reveals the interface between $\mathrm{h}-\mathrm{BN}$ and $\mathrm{B}_{2} \mathrm{O}_{3}$. The inset of Figure $2 \mathrm{~b}$ shows the selected area electron diffraction (SAED) pattern corresponding to (002), (101), (004), and (110) lattice planes of h-BN and reveals the crystalline phase of $\mathrm{h}-\mathrm{BN}$, consistent with the X-ray diffraction (XRD) results (Figure S1a). The high-magnification TEM image in Figure $2 \mathrm{c}$ shows randomly oriented layers of h-BN and indicates the $\mathrm{B}_{2} \mathrm{O}_{3}$ matrix in the darker regions. The fast Fourier transform patterns (in Figure 2c) display hexagonal spots with rotation angle of about $11^{\circ}$, which is also corroborated by Figure $2 \mathrm{~d}$, which shows an array of h-BN atoms arranged periodically in a hexagonal symmetry with the lattice constant like the values of bulk h-BN, as previously reported. ${ }^{25}$

2.3. Structural Analysis. XPS shows the distribution of elemental boron (B), nitrogen $(\mathrm{N})$, oxygen $(\mathrm{O})$, and carbon (C) in the samples, Figure 2e. The major peaks of these elements were present at 194.2, 398.1, 535, and $287 \mathrm{eV}$. The observation is in close agreement with previous reports. ${ }^{25,26}$ Boron, nitrogen, and oxygen 1s-core levels bear the signature of the formation of $\mathrm{hBN}-\mathrm{B}_{2} \mathrm{O}_{3}$ composites. ${ }^{27,28}$ Carbon pick up is from the SPS graphite mold.

The XRD pattern of all $\mathrm{hBN}-\mathrm{B}_{2} \mathrm{O}_{3}$ composites shown in the Supporting Information Figure S1a, indicates hexagonal h-BN structure with the two major diffraction peaks at $26.56^{\circ}$ (002) and $41.46^{\circ}$ (100). With increase in $\mathrm{B}_{2} \mathrm{O}_{3}$ content peak, broadening is observed and a low intensity peak of $\mathrm{B}_{2} \mathrm{O}_{3}$ appears as a shoulder adjacent to the high intensity h-BN peak at $26.56^{\circ}$. The broadening of the peaks confirms a fine-grained microstructure. The intensity of this peak increases with the doping concentration of $\mathrm{B}_{2} \mathrm{O}_{3}$. A low intensity $\mathrm{B}_{2} \mathrm{O}_{3}$ peak was also observed at $14.34^{\circ}$. The Raman spectrum in Supporting Information Figure S1b shows peaks associated with the B-N and $\mathrm{B}-\mathrm{O}$ bonds at wave numbers 1417,1730 , and $1961 \mathrm{~cm}^{-1}$, corresponding to $\mathrm{B}-\mathrm{N}$ stretching vibrations. ${ }^{19}$ Differential thermal analysis (DTA) results from Supporting Information Figure S1c indicate the presence of various endothermic as well as exothermic peaks. The peak at $449{ }^{\circ} \mathrm{C}$ occurs due to diffusion of $\mathrm{B}_{2} \mathrm{O}_{3}$ into h-BN, ${ }^{29}$ whereas the other peaks are due to impurity phases and moisture. The endothermic peaks at 164 and $441{ }^{\circ} \mathrm{C}$ appear due to boron trioxide and h-BN in the initial mixture. The thermogravimetric (TG) curve indicates weight loss with temperature in the sample. The Supporting Information Figure S2a shows a decrease in surface area with h$\mathrm{BN}$ content, and the values lie between 0.97 and $14.43 \mathrm{~m}^{2} / \mathrm{g}$. The evaporation of $\mathrm{B}_{2} \mathrm{O}_{3}$ is responsible for the formation of pores and increase in surface area during sintering at high temperatures. The high surface area of $\sim 14.43 \mathrm{~m}^{2} / \mathrm{g}$ for the $10 \mathrm{BNBO}$ sample was possibly due to the amorphous nature of $\mathrm{B}_{2} \mathrm{O}_{3}{ }^{30}$ The Supporting Information Figure $\mathrm{S} 2 \mathrm{~b}$ shows the variation in density of the composites with $\mathrm{B}_{2} \mathrm{O}_{3}$ content.

2.4. Contact Angle Study. The hydrophilicity of the composites is critical to explain biocompatibility and degradability of the samples, as it controls cell suspension and transfer of body fluids. The contact angles of all of the composites were measured and are shown in Supporting Information Figure $\mathrm{S} 3 \mathrm{a}-\mathrm{d}$. It was observed from the figure that the contact angle values increase with $\mathrm{h}-\mathrm{BN}$ concentration from $53.44^{\circ}$ for 10BNBO to $75.65^{\circ}$ for $90 \mathrm{BNBO}$.

2.5. Mechanical Analysis. The compressive stress-strain curves for pure h-BN, 50BNBO, and 90BNBO samples, indicated by curves $1-3$ respectively, are shown in Figure 3 a.
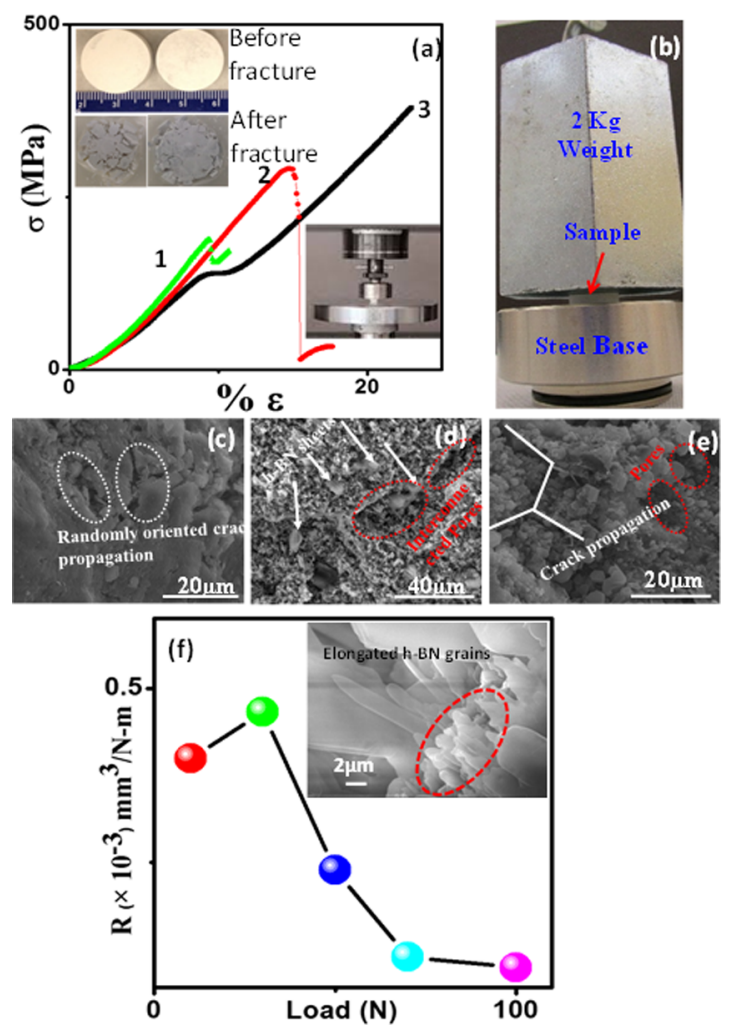

Figure 3. Mechanical characterizations of the SPS-sintered $\mathrm{BN}-\mathrm{B}_{2} \mathrm{O}_{3}$ composites. (a) Variation of $\sigma$ vs $\varepsilon$. The inset shows the samples before and after fracture test. (b) Load bearing capacity authenticated by placing a $2 \mathrm{~kg}$ weight on the sample without damage or fracture. (c, d) Low magnification, SEM image revealing the randomly oriented crack propagation. (e) High-magnification SEM image of fractured $\mathrm{BNBO}$ sample reveal in the h-BN sheets interlocking the crack propagation. The inset shows elongated h-BN grains. (f) Variation of specific wear rate with load for $90 \mathrm{BNBO}$ composite.

The tests were conducted using an Instron universal testing machine (UTM) (Figure 3a). Digital images of samples before and after fracture are also shown in the inset. The maximum compressive strength of $291 \mathrm{MPa}$ was observed for the sample with composition $90 \mathrm{BNBO}$ having a density $1.9 \mathrm{~g} / \mathrm{cm}^{3}$; thereby yielding a bone material index of 153 . This value is superior to trabecular human bone having density $1.8 \mathrm{~g} / \mathrm{cm}^{3}$ and compressive strength of $221 \mathrm{MPa}$ having a material index of 123. ${ }^{31}$ This observation fulfills the mechanical criteria for this material as a possible substitute to commercial bone implant materials in use. A comparison of the synthesis method, mechanical properties, porosity, and Brunauer-Emmett-Teller (BET) surface area for porous nanostructured 3D graphene and h-BN synthesized by SPS is listed in Table 1 . It is observed from the table that the $3 \mathrm{D}$ h-BN exhibits better mechanical properties in comparison to other reported ceramic biomaterials, viz. HAp, ${ }^{32,33}$ tricalcium phosphate, ${ }^{34}$ and HAp-based composites. ${ }^{35}$ These biomaterials possess lower strength in comparison to the metallic implants produced by the laser engineered net shaping method. ${ }^{36}$ This may be due to randomly oriented large h-BN sheets along different crystallographic planes.

The microstructural behavior of the fractured $\mathrm{h}-\mathrm{BN}$ and BNBO samples after compressive loading was also studied. Figure $3 \mathrm{~b}$ shows the real-time load bearing capacity of the samples, with a $2 \mathrm{~kg}$ block being placed over the sample. The 
Table 1. Porosity and Mechanical Properties of Different Bone Implants

\begin{tabular}{|c|c|c|c|c|c|c|}
\hline bone implant materials & $\begin{array}{l}\text { density } \\
\left(\mathrm{g} / \mathrm{cm}^{3}\right)\end{array}$ & $\begin{array}{l}\text { porosity } \\
(\%)\end{array}$ & $\begin{array}{l}\text { BET surface area } \\
(\mathrm{m} / \mathrm{g})\end{array}$ & $\begin{array}{l}\text { compressive strength } \\
(\mathrm{MPa})\end{array}$ & $\begin{array}{l}\text { Young's modulus } \\
\text { (MPa) }\end{array}$ & references \\
\hline titanium (porous) & 4.5 & 48 & & $54 \pm 5$ & $7.7 \pm 2$ & 29,36 \\
\hline HAp & 2.1 & 41 & 15 & $34 \pm 2$ & & 32,33 \\
\hline $0.5 \mathrm{MgO}-\mathrm{HAp}$ (microwave irradiation) & 3.04 & $\sim 6$ & 21.87 & $21 \pm 1$ & 126.31 & 35 \\
\hline $50 \mathrm{BN}-50 \mathrm{~B}_{2} \mathrm{O}_{3}$ (thin film) & 1.3 & $\sim 36.4$ & 2.500 & $37 \pm 5$ & & 22 \\
\hline tricalcium phosphate & 3.14 & 50 & $12 \pm 2$ & $11 \pm 1.3$ & & 34 \\
\hline three-dimensional graphene (SPS) & $\sim 1.42$ & 42 & & $40 \pm 3$ & $4.1 \pm 0.5$ & 21 \\
\hline three-dimensional h-BN (SPS) & 1.90 & $\sim 10$ & 1.326 & $281 \pm 1$ & $63.65 \pm 0.5$ & current work \\
\hline
\end{tabular}

fracture image of the h-BN sample, as shown in Figure 3c, shows big h-BN sheets along with high amount of porosity with minimal strength and load bearing capacity. On the contrary, the fracture image of the BNBO samples in Figure 3d,e yields an interconnected microstructure, as also observed from the subsequent simulations studies, leading to their higher strength; in concurrence with the compression plot in Figure 3a. The predominance of elongated $\mathrm{h}-\mathrm{BN}$ grains in the fractured microstructure, as seen in the inset of the Figure $3 \mathrm{a}$, is attributed to the grain growth induced in presence of $\mathrm{B}_{2} \mathrm{O}_{3}$ and may lead to an improved toughness in the composites. To validate the mechanical behavior of the synthesized BNBO composites, the wear rate " $W_{\mathrm{s}}$ " was also evaluated, as shown in Figure $3 \mathrm{f}$. From the figure, the specific wear rate was observed to decrease exponentially with load. The higher wear rate during the initial loading is due to breaking of weaker van der Waals bonds between adjacent h-BN sheets in the h-BNdominated regions of the matrix; the subsequent decrease in wear rate is due to presence of strong covalent bonding between h-BN and $\mathrm{B}_{2} \mathrm{O}_{3}$ in the remaining part of the matrix.

2.6. Molecular Dynamics Simulation of 3D Composites. To establish the effect of SPS processing on mechanical property enhancement in the $\mathrm{BNBO}$ composites, a molecular dynamics (MD) simulation was performed. The MD was separated into two parts; the first part tries to mimic the SPS process where $\mathrm{B}_{2} \mathrm{O}_{3}$ is mixed with h-BN nanosheets and a compressive strain (load) was applied at constant velocity until the structure reduces its original size up to $60 \%$, as shown in Figure 4a (state 1), followed by the compressive force being slowly released (unload) till the applied force is 0 (state 2 ). In the second part, the resulting BNBO composite is subjected to a mechanical test through a tensile strain, as shown in the inset of Figure 4a.

The snapshots in Figure 4a clearly show that the $\mathrm{B}_{2} \mathrm{O}_{3}$ and h$\mathrm{BN}$ nanosheets react covalently leading to a $3 \mathrm{D}$ interconnected network in the composite. The snapshot "state 1 " shows the composite at its maximum strain and "state 2 " represents the 3D structure in its final relaxed state. The hysteresis in the compressive strain curve represents the permanent deformation in the BNBO structure. The tensile strain curves in the inset of the Figure 4a show the force necessary to stretch up the BNBO composite compared to a pure h-BN structure. In the composite case, a larger force is required to pull apart the h$\mathrm{BN}$ nanosheets due to the covalent bonds formed between $\mathrm{B}_{2} \mathrm{O}_{3}$ and h-BN during the simulated SPS process, in contrast to the pure h-BN nanosheets, where only van der Waals forces are present along the pulling direction. The snapshots showed in the Figure $4 \mathrm{~b}$ represent four different stages of the compressive/tensile strain of the BNBO composite.

2.7. In Vitro Cytotoxicity to Mice Calvarial Osteoblast (MCO) Cells. The toxicity study of the different compositions was performed on mice calvarial osteoblast (MCO) cells. The samples showed no significant toxicity on $\mathrm{MCO}$ cells at different concentrations ranging from 1 to $100 \mu \mathrm{g} / \mathrm{mL}$. In Figure 5a, treatment with $25 \mu \mathrm{g} / \mathrm{mL}(\sim 58 \%, p<0.01), 50 \mu \mathrm{g} /$ $\mathrm{mL}(\sim 77 \%, p<0.01)$, and $100 \mu \mathrm{g} / \mathrm{mL}(\sim 69 \%, p<0.01)$ of 90BNBO showed significant proliferation of osteoblast cells as compared to control. However, MCO cells treated with 1 and 5 $\mu \mathrm{g} / \mathrm{mL}$ of $90 \mathrm{BNBO}$ composite powder showed a fall in cell viability as compared to control. There were no statistically significant changes in proliferation/viability of osteoblast cells with the other samples having higher $\mathrm{B}_{2} \mathrm{O}_{3}$ content.

2.8. Osteogenic Activity Analysis. The osteogenic activity of the composites was investigated by MTT assay. ${ }^{37,38}$ MCO cells were cultured for 21 days with and without the sample, fixed in $4 \%$ paraformaldehyde, and drops of alizarin red-S was added, which stains the calcium deposition. The 90BNBO sample revealed significant increase in mineralization. Quantification of mineralization yields significant increase in mineralized nodule formation in the presence of 90BNBO. Data from this study suggest that the 90BNBO sample at concentrations $10 \mathrm{nM}(p<0.05), 100 \mathrm{pM}(p<0.05)$, and $1 \mathrm{pM}(p<0.01)$ was found to be potent, and showed increase in mineralization by $\sim 34 \%(10 \mathrm{nM}), \sim 53 \%(100 \mathrm{pM})$, and $\sim 91 \%$ ( $1 \mathrm{pM}$ ) over the control (untreated cells), as shown in Figure 5 b. However, there were no statistically significant changes in mineralization of osteoblast cells with the other samples having higher $\mathrm{B}_{2} \mathrm{O}_{3}$ content. These investigations clearly point out the potency of the current developed composites to be used clinically as bone implant materials.

\section{CONCLUSIONS}

Three-dimensional nanostructured high strength $\mathrm{hBN}-\mathrm{B}_{2} \mathrm{O}_{3}$ composites were synthesized using SPS and their microstructure and properties were correlated. A highly interconnected network was observed in the microstructural observations. $\mathrm{B}_{2} \mathrm{O}_{3}$ enhances densification and influences the grain orientation in h-BN. Samples could be sintered to high density at an abnormally low temperature of only $250{ }^{\circ} \mathrm{C}$ in 2 min possessing a high compressive strength of $\sim 291 \mathrm{MPa}$. For investigating the suitability of these materials as possible implant substitutes, cell viability and proliferation tests were investigated. The results show significant effect of 90BNBO composite on cell viability/proliferation. The same composition also shows good mineralized nodule formation over control and suggests its use as an osteogenic agent in bone formation. The substantially high material index (compared to human bone), extremely good mechanical properties, and impressively high cell culture performance makes this composite material a promising candidate for use in knee and bone implants. 


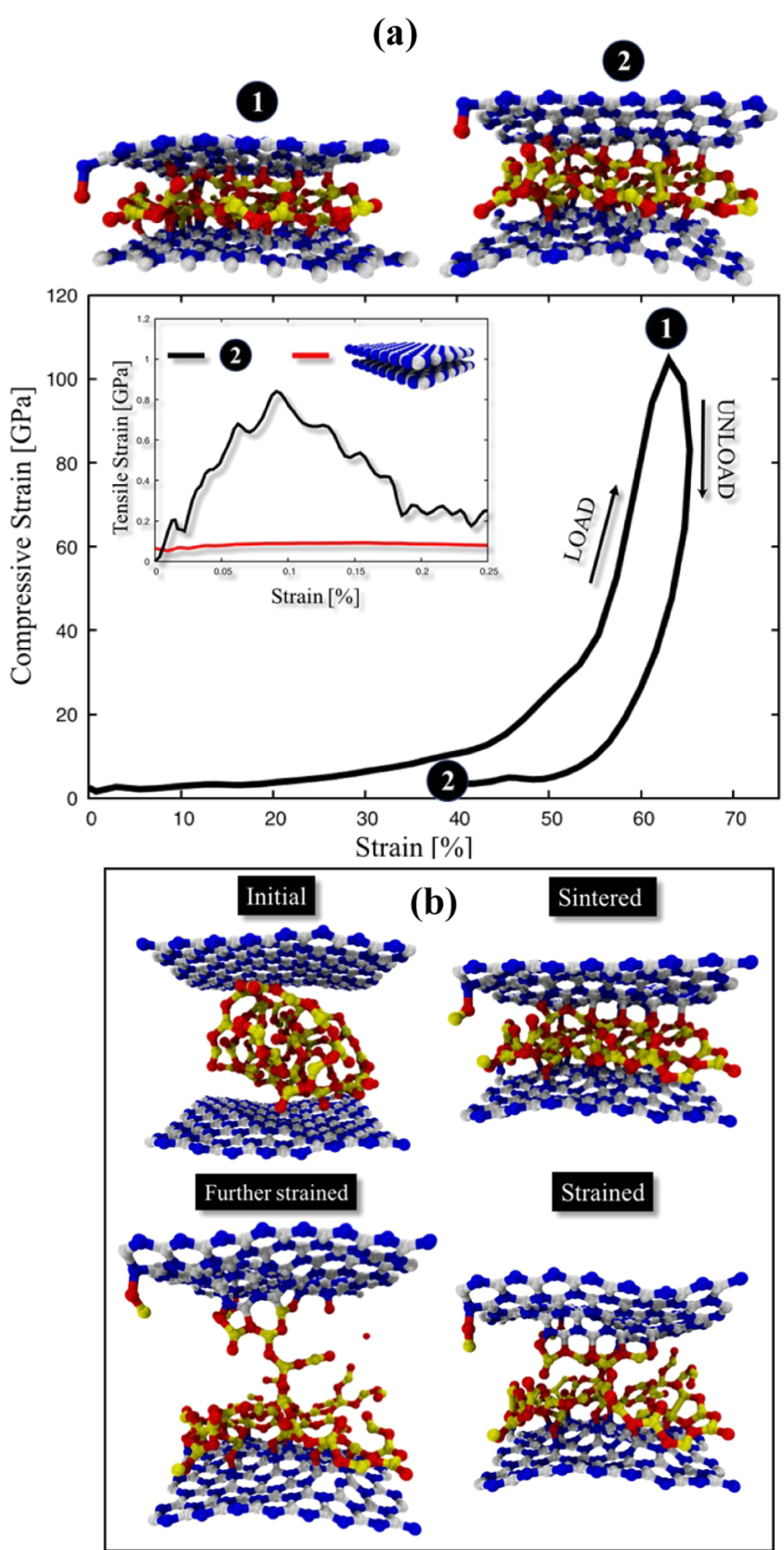

Figure 4. MD simulation of BNBO: (a) compressive strain curve for the BNBO composite formation. The symbols " 1 " and "2" represent the BNBO mixture at maximum compression $(\sim 60 \%)$ and the formed BNBO composite, respectively. The inset shows the required force (tensile strain) to stretch the BNBO composite compared to a pure $\mathrm{h}$ $\mathrm{BN}$ structure. (b) Snapshots of the entire simulation process. (1) "Initial": the initial configuration, a mixture of h-BN/ $\mathrm{B}_{2} \mathrm{O}_{3}$; (2) "sintered": the structure at maximum compression $(60 \%)$; and $(3,4)$ "strained": the BNBO composite under tensile strain in two different stages.

\section{METHODS AND MATERIALS}

4.1. Synthesis of h-BN Composites. In the present study, a series of composites in the system $x[\mathrm{~h}-\mathrm{BN}]-(100-$ $x)\left[\mathrm{B}_{2} \mathrm{O}_{3}\right](x=10,50,70,90 \mathrm{~mol} \%)$ were prepared using analytical reagent grade chemicals comprising h-BN (SigmaAldrich, 99.99\%) and $\mathrm{B}_{2} \mathrm{O}_{3}$ (Sigma-Aldrich, 99.99\%). The appropriate amounts of these chemicals were calculated based on the composition of the composite and they were weighed using an electronic balance (Shimadzu make), mixed in a mortar and pestle using an acetone medium for $6 \mathrm{~h}$, dried, and calcined at $1000{ }^{\circ} \mathrm{C}$ in an electric furnace to remove the volatile impurities. Subsequently, these powders were processed in SPS at different sintering conditions. SPS was performed in a Dr Sinter 1050 apparatus (SPS Syntex Inc., Japan). The sintering conditions are as follows: the temperature was between 150 and $250{ }^{\circ} \mathrm{C}$, applied pressure was 20 and $30 \mathrm{MPa}$, ramp rate was 75 ${ }^{\circ} \mathrm{C} / \mathrm{min}$ with $2 \mathrm{~min}$ dwell. Samples of $15 \mathrm{~mm}$ diameter and thickness 5.95-8.02 mm were prepared.

4.2. Material Characterization. XRD was done using $\mathrm{Cu}$ $\mathrm{K} \alpha$ radiation in a Rigaku D/Max Ultima II equipment. Elemental analysis for different chemical compositions was carried out using X-ray photoelectron spectroscopy (XPS, PHI Quantera XPS) on a PHI-5000C ESCA system. Thermogravimetric analysis (TGA) and differential thermal analysis (DTA) were carried out in a SDTQ-600 thermal analyzer from room temperature to $400{ }^{\circ} \mathrm{C}$ at $5{ }^{\circ} \mathrm{C} / \mathrm{min}$ under flowing $\mathrm{N}_{2}$. The BET surface area analysis was carried out in a Quanta Chrome Autosorb-3b BET Surface Analyzer. An FEI Quanta 400 SEM was used at $10 \mathrm{kV}$ for microstructure observations. The sample was sputtered with gold film to prevent charging. The TEM images and SAED patterns were obtained in a JEOL 2100 field emission gun transmission electron microscope. Instron universal testing machine (UTM) was used to obtain the load versus displacement curves from the samples at room temperature. For wear test a pin-on-disc-type machine (DUCOM model TR-20LE) was used in the dry condition. Tangential frictional force and wear were monitored and recorded. Specific wear rate was obtained from

$$
W_{\mathrm{s}}=\frac{(\Delta V) 1000}{L P}=\frac{\left(\left(m_{1}-m_{2}\right) / \rho\right) 1000}{L P}
$$

where, $\Delta V$ : volume loss $\left(\mathrm{mm}^{3}\right), \rho$ : density of sample $\left(\mathrm{g} / \mathrm{cm}^{3}\right)$, $P$ : applied load $(\mathrm{N}), L$ : sliding distance $(\mathrm{m}), m_{1}$ and $m_{2}$ are the weights before and after test.

Contact angle was measured using an Advanced goniometer (500, Rame-Hart, Inc.) under equilibrium conditions.

4.3. Cell Culture and MTT Assay. For each experiment of MTT and mineralization, about 5-10 calvaria were collected from new born Bal b/c mice pups. They were removed from the skull surgically; sutures were separated and soft tissues were removed by scrapping. The calvariae were kept together for repeated digestion in dispase and collagenase $\mathrm{P}$ enzymes $(0.1 \%$ each) for release of cells, and the supernatant was discarded. Cells from subsequent three to four digestions were pooled and cultured in $\alpha$-MEM supplemented with 10\% FCS and $1 \%$ penicillin/streptomycin at $37^{\circ} \mathrm{C}$ in a humidified atmosphere. ${ }^{39}$

The toxicity experiments for all of the synthesized compositions were performed on mice calvarial osteoblast (MCO) cells. The seed density was $2.0 \times 10^{3}$ cells/well in a 96well plate and cultured as before with and without the samples at different concentrations ranging from 1 to $100 \mu \mathrm{g} / \mathrm{mL}$. MTT assay was done to check the cell viability. ${ }^{40}$ The cells were incubated for $3 \mathrm{~h}$ with MTT reagent at a concentration of 0.5 $\mathrm{mg} / \mathrm{mL}$, washed with phosphate-buffered saline (PBS), and dimethyl sulphoxide was added for dissolving the formazan.

MCO cells with seed density $10.0 \times 10^{3}$ cells/well in 12 -well plates were cultured with and without samples and treated at concentrations ranging from $100 \mu \mathrm{M}$ to $1 \mathrm{pM}$ for 21 days; the media was refreshed once every $48 \mathrm{~h}$. After experimentation, the cells were washed with PBS, fixed with $4 \%$ paraformaldehyde, stained with alizarin red-S (40 mM, pH 4.5) for $30 \mathrm{~min}$, 
(a)

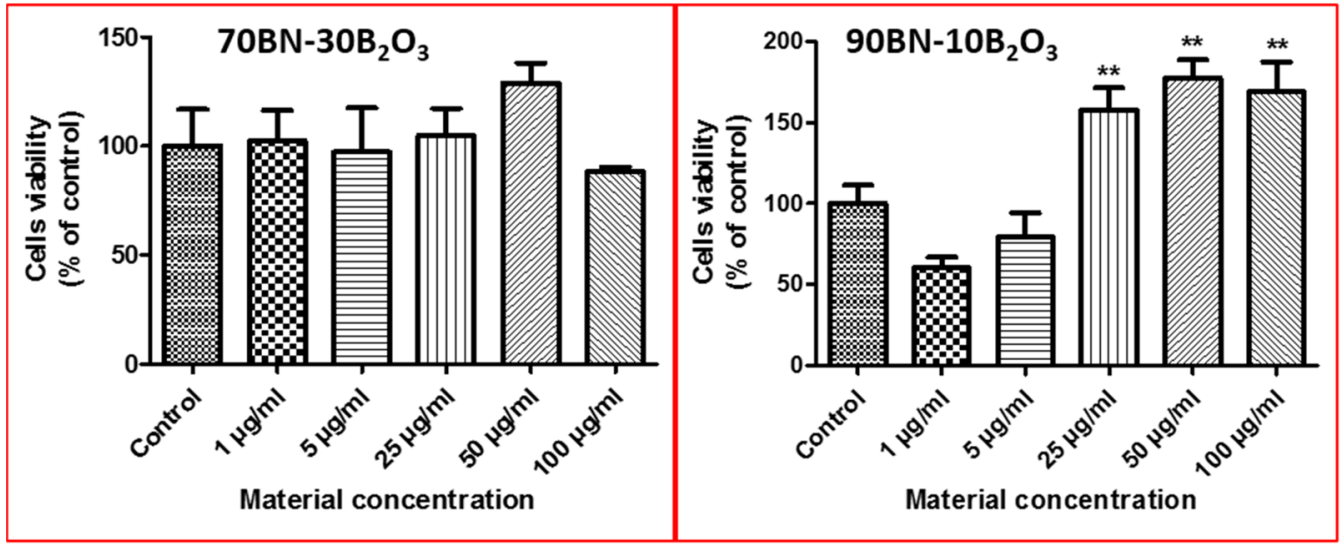

(b)
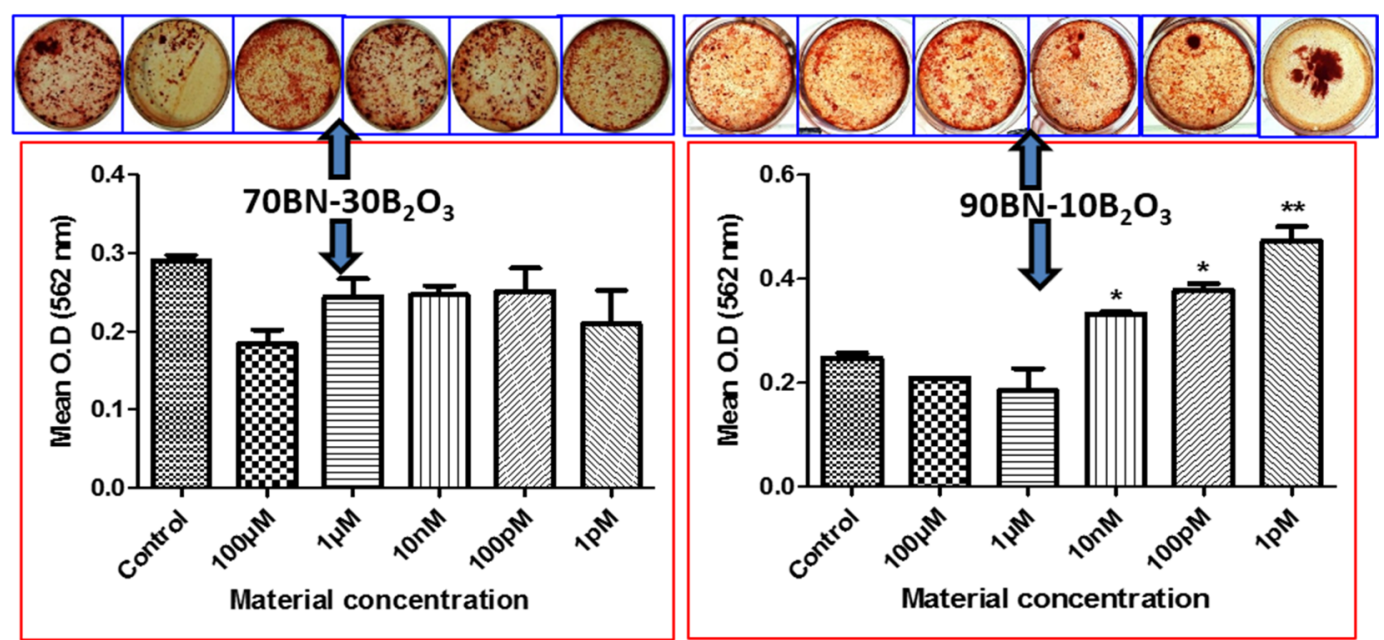

Figure 5. (a) $90 \mathrm{BNBO}$ composition increases cell proliferation of mouse calvarial osteoblast (MCO) cells. Cells were cultured in differentiation medium and treated with various concentrations of the $90 \mathrm{BNBO}$ samples ranging from 1 to $100 \mu \mathrm{g} / \mathrm{mL}$ for 48 h, and cell viability was assessed by MTT assay. The percent viable cells were calculated compared to untreated cells taken as control. Data represent the mean \pm SEM $(* * p<0.01$ compared to control). (b) Mice calvarial osteoblasts cells were grown in osteoblast differentiation medium. Cultures were maintained for 21 days. At the end of the experiments, cells were stained with alizarin red-S. Upper panel: representative photomicrographs showing mineralized nodules in various groups with or without treatment. Lower panel: alizarin red-S dye was extracted and mineralization quantified spectrophotometrically. Data represent the mean \pm SEM $(* p<0.05$ and $* * p<0.01$ compared to control).

and washed with water to remove the unbound stain. ${ }^{41}$ Photographs of stained cells were captured and alizarin red-S stain was extracted using $10 \%$ cetylpyridiniumchloride (CPC), which was used to quantify the bound stain. The extracted stain was solubilized in $10 \%$ CPC with gentle shaking. The absorbance of the solubilized stain was read at $562 \mathrm{~nm}$ using a microplate spectrophotometer. The data were analyzed using one-way ANOVA followed by the Newman-Keuls test of significance with software Graph Pad Prism version 5.0. Probability $p<0.05$ was considered statistically significant.

4.4. Simulation. MD simulations were carried out using the open source software LAMMPS ${ }^{42}$ with the fully atomistic reactive force field called ReaxFF. ${ }^{43}$ ReaxFF allows the chemical reactions as bond formation and/or breaking to be accurately estimated by parameterization through experimental data and the density functional theory calculations. The parameterization used in this work is described elsewhere. ${ }^{44}$ The structures subjected to the compressive strain were initially equilibrated during $200 \mathrm{ps}$ under NPT at $300 \mathrm{~K}$ and no pressure using Nose-Hoover integrator scheme. ${ }^{45}$ The simulation box was kept within the periodic boundary conditions along all directions to avoid any border effect. The tensile strain case the periodicity along $z$ direction was removed to allow the outer h-BN sheets to be pulled up through their center of mass. The strain velocity in all cases was kept $0.002 \AA / \mathrm{fs}$ and the time step $0.1 \mathrm{fs}$.

\section{ASSOCIATED CONTENT}

\section{Supporting Information}

The Supporting Information is available free of charge on the ACS Publications website at DOI: 10.1021/acsomega.8b00707.

$\mathrm{MD}$ simulation ( $\mathrm{hBN}-\mathrm{B}_{2} \mathrm{O}_{3}$ under compression) (AVI) Structural characterizations of SPS-sintered $\mathrm{hBN}-\mathrm{B}_{2} \mathrm{O}_{3}$ composites (XRD, Raman spectroscopy, DTA, and TGA); surface area, density with increasing content of $\mathrm{B}_{2} \mathrm{O}_{3}$, and contact angle study (PDF) 


\section{AUTHOR INFORMATION}

\section{Corresponding Author}

*E-mail: gautam_ceramic@yahoo.com. Tel: +91-8840389015.

ORCID ${ }^{\circ}$

Chandkiram Gautam: 0000-0003-3190-5577

Robert Vajtai: 0000-0002-3942-8827

Douglas S. Galvao: 0000-0003-0145-8358

\section{Present Address}

${ }^{\propto}$ Department of Materials Science and Engineering, Indian Institute of Technology, Gandhinagar, Gujarat (India)

\section{Author Contributions}

The present research work was conceived and supervised by P.M.A. and R.V. Materials synthesis, fabrication, and manuscript writing were performed by C.G., S.J., D.C., and A.G. Materials testing was performed by S.B., C.S.T., V.K.M., N.A., S.O., and R.T. The theoretical simulation led by C.F.W. and D.S.G.

Notes

The authors declare no competing financial interest.

\section{ACKNOWLEDGMENTS}

The authors acknowledge the funding support from the U.S. Air Force Office of Scientific Research Award No. FA9550-141-0268 and FA9550-12-1-0035. C.G. acknowledges the financial support from UGC Government of India, under the Raman Fellowship scheme Award No. F5-65/2014 (IC). D.C. acknowledges DST, Govt. of India, for the SPS facility. C.F.W. thanks FAPESP Grant No. 2016/12340-9 and FAPESP/ CEPID Grant No. 2013/08293-7 for financial support. We also acknowledge to Center of Excellence, Science and Technology, Government of Uttar Pradesh for providing XRD facility at Department of Physics, University of Lucknow, India.

\section{REFERENCES}

(1) Yin, J.; Li, X.; Zhou, J.; Guo, W. Ultralight three-dimensional boron nitride foam with ultralow permittivity and superelasticity. Nano Lett. 2013, 13, 3232-3236.

(2) Zeng, H.; Zhi, C.; Zhang, Z.; Wei, X.; Wang, X.; Guo, W.; Bando, Y.; Golberg, D. White Graphenes: boron nitride nanoribbons via boron nitride nanotube unwrapping. Nano Lett. 2010, 10, 5049-5055.

(3) Zhi, C. Y.; Bando, Y.; Tang, C. C.; Kuwahara, H.; Golberg, D. Large-scale fabrication of boron nitride nanosheets and their utilization in polymeric composites with improved thermal and mechanical properties. Adv. Mater. 2009, 21, 2889-2893.

(4) Gao, R.; Yin, L.; Wang, C.; Qi, Y.; Lun, N.; Zhang, L.; Liu, Y. X.; Kang, L.; Wang, X. High-yield synthesis of boron nitride nanosheets with strong ultraviolet cathodoluminescence emission. J. Phys. Chem. C 2009, 113, 15160-15165.

(5) Siria, A.; Poncharal, P.; Biance, A. L.; Fulcrand, R.; Blase, X.; Purcell, S. T.; Bocquet, L. Giant osmotic energy conversion measured in a single transmembrane boron nitride nanotube. Nature 2013, 494, $455-458$.

(6) Alauzun, J. G.; Ungureanu, S.; Brun, N.; Bernard, S.; Miele, P.; Backov, R.; Sanchez, C. Novel monolith-type boron nitride hierarchical foams obtained through integrative chemistry. J. Mater. Chem. 2011, 21, 14025-14030.

(7) Schlienger, S.; Alauzun, J.; Michaux, F.; Vidal, L.; Parmentier, J.; Gervais, C.; Babonneau, F.; Bernard, S.; Miele, P.; Parra, J. B. Micromesoporous boron nitride- based materials templated from zeolites. Chem. Mater. 2012, 24, 88-96.

(8) Sun, H.; Xu, Z.; Gao, C. Multifunctional, ultra-flyweight, synergistically assembled carbon aerogels. Adv. Mater. 2013, 25, 2554-2560.
(9) Kim, K. H.; Oh, Y.; Islam, M. F. Graphene coating makes carbon nanotube aerogels superelastic and resistant to fatigue. Nat. Nanotechnol. 2012, 7, 562-566.

(10) Niu, Z.; Chen, J.; Hng, H.-H.; Ma, J.; Chen, X. A Leavening Strategy to Prepare Reduced Graphene Oxide Foams. Adv. Mater. 2012, 24, 4144-4150.

(11) Xu, Y.; Sheng, K.; Li, C.; Shi, G. Self-assembled graphene hydrogel via a one-step hydrothermal process. ACS Nano 2010, 4, 4324-4330.

(12) Gao, L.; Li, J. Preparation of nanostructured hexagonal boron nitride powder. J. Am. Ceram. Soc. 2003, 11, 1982-1984.

(13) Coblenz, W. S.; Lewis, D., III In situ reaction of $\mathrm{B}_{2} \mathrm{O}_{3}$ with AlN and/or $\mathrm{Si}_{3} \mathrm{~N}_{4}$ to form $\mathrm{BN}$ toughened composites. J. Am. Ceram. Soc. 1988, 71, 1080-1085.

(14) Weng, Q. H.; Wang, X. B.; Bando, Y.; Golberg, D. One-step template-free synthesis of highly porous boron nitride microsponges for hydrogen storage. Adv. Energy Mater. 2014, 4, No. 1301525.

(15) Song, Y.; Li, B.; Yang, S.; Ding, G.; Zhang, C.; Xie, X. Ultralight boron nitride aerogels via template-assisted chemical vapor deposition. Sci. Rep. 2015, 5, No. 10337.

(16) Golberg, D.; Bando, Y.; Huang, Y.; Terao, T.; Mitome, M.; Tang, C.; Zhi, C. Boron nitride nanotubes and nanosheets. ACS Nano 2010, 4, 2979-2993.

(17) Lin, Y.; Connell, J. W. Advances in 2D boron nitride nanostructures: nanosheets, nanoribbons, nanomeshes and hybrids with graphene. Nanoscale 2012, 4, 6908-6939.

(18) Meziani, M. J.; Song, W.; Wang, P.; Lu, F.; Hou, Z.; Anderson, A.; Maimaiti, H.; Sun, Y. Boron nitride nanomaterials for thermal management applications. ChemPhysChem 2015, 16, 1339-1346.

(19) Li, X.; Hao, X.; Zhao, M.; Wu, Y.; Yang, J.; Tian, Y.; Qian, G. Exfoliation of hexagonal boron nitride by molten hydroxides. $A d v$. Mater. 2013, 25, 2200-2204.

(20) Santanach, J. G.; Weibel, A.; Estournes, C. Q.; Laurent, Y.; Peigney, A.; Yang, Q. Spark plasma sintering of alumina: study of parameters, formal sintering analysis and hypothesis on the mechanism(s) involved in densification and grain growth. Acta Mater. 2011, 59, 1400-1408.

(21) Chakravarty, D.; Tiwary, C. S.; Woellner, C. F.; Radhakrishnan, S.; Vinod, S.; Ozden, S.; Autreto, P. A. D.; Bhowmick, S.; Asif, S.; Mani, S. A.; Galvao, D. S.; Ajayan, P. M. 3D porous graphene by lowtemperature plasma welding for bone implants. Adv. Mater. 2016, 28, 8959-8967.

(22) Gautam, C. R.; Tiwary, C. S.; Machado, L. D.; Jose, S.; Ozden, S.; Biradar, S.; Galvao, D. S.; Sonker, R. K.; Yadav, B. C.; Vajtaia, R.; Ajayan, P. M. Synthesis and porous h- bn 3D architectures for effective humidity and gas sensors. RSC Adv. 2016, 6, 87888-87896.

(23) Zhi, C.; Bando, Y.; Tang, C. C.; Golberg, D.; et al. Phonon characteristics and cathodolumininescence of boron nitride nanotubes. Appl. Phys. Lett. 2005, 86, No. 213110.

(24) Kusari, U.; Bao, Z.; Cai, Y.; Ahmad, G.; Sandhage, K. H.; Sneddon, L. G. Formation of nanostructured, nanocrystalline boron nitride microparticles with diatom-derived 3-D Shapes. Chem. Commun. 2007, 1177-1179.

(25) Gautam, C.; Tiwary, C. S.; Jose, S.; Brunetto, G.; Ozden, S.; Vinod, S.; Raghavan, P.; Biradar, S.; Galvao, D. S.; Ajayan, P.-M. Synthesis of low-density, carbon-doped, porous hexagonal boron nitride solids. ACS Nano 2015, 9, 12088-12095.

(26) Lei, W. W.; Portehault, D.; Liu, D.; Qin, S.; Chen, Y. Porous boron nitride nanosheets for effective water cleaning. Nat. Commun. 2013, 4, No. 1777.

(27) Zhang, C.; Zhao, S.; Jin, C.; Koh, A. L.; Zhou, Y.; Xu, W.; Li, Q.; Xiong, Q.; Peng, H.; Liu, Z. Direct growth of large-area graphene and boron nitride heterostructures by a co-segregation method. Nat. Commun. 2015, 6, No. 6519.

(28) Ci, L.; Song, L.; Jin, C.; Jariwala, D.; Wu, D.; Li, Y.; Srivastava, A.; Wang, Z. F.; Storr, K.; Balicas, L.; Liu, F.; Ajayan, P. M. Atomic layers of hybridized boron nitride and graphene domains. Nat. Mater. 2010, 9, 430-435. 
(29) Tang, C. C.; Bando, Y.; Huang, Y.; Zhi, C. Y.; Golberg, D. Synthetic routes and formation mechanisms of spherical boron nitride nanoparticles. Adv. Funct. Mater. 2008, 18, 3653-3661.

(30) Lee, S. K.; Eng, P. J.; Mao, H.; Meng, Y.; Newville, M.; Hu, M. Y.; Shu, J. Probing of bonding changes in $\mathrm{B}_{2} \mathrm{O}_{3}$ glasses at high pressure with inelastic X-ray scattering. Nat. Mater. 2005, 4, 851-854.

(31) Carter, D. R.; Hayes, W. C. Bone compressive strength: the influence of density and strain rate. Science 1976, 194, 1174-1176.

(32) Bose, S.; Roy, M.; Bandyopadhyay, A. Recent Advances in Bone Tissue Engineering Scaffolds. Trends Biotechnol. 2012, 30, 546-554.

(33) Singh, A.; Purohit, K. M. Chemical synthesis, characterization and bioactivity evaluation of hydroxyapatite prepared from garden snail (helix aspersa). J. Bioprocess. Biotech. 2011, 1, 1-5.

(34) Tarafder, S.; Balla, V. K.; Davies, N. M.; Bandyopadhyay, A.; Bose, S. Microwave- sintered 3d printed tricalcium phosphate scaffolds for bone tissue engineering. J. Tissue Eng. Regener. Med. 2013, 7, 631641.

(35) Gautam, C. R.; Kumar, S.; Biradar, S.; Jose, S.; Mishra, V.-K. Synthesis and enhanced mechanical properties of $\mathrm{MgO}$ substituted hydroxyapatite: a bone substitute material. RSC Adv. 2016, 6, 6756567574.

(36) Xue, W.; Krishna, B.-V.; Bandyopadhyay, A.; Bose, S. Processing and biocompatibility evaluation of laser processed porous titanium. Acta Biomater. 2007, 3, 1007-1018.

(37) Sun, L.; Chow, L. C.; Frukhtbeyn, S. A.; Bonevich, J. E. Preparation and properties of nanoparticles of calcium phosphates with various $\mathrm{Ca} / \mathrm{P}$ ratios. J. Res. Natl. Inst. Stand. Technol. 2010, 115, 243-255.

(38) Ahmad, N.; Chillara, R.; Kushwaha, P.; Khedgikar, V.; Karvande, A.; Choudhary, D.; Adhikary, S.; Maurya, R.; Trivedi, R. Evaluation of anti-osteoporotic activity of butanolic fraction from passiflora foetida in ovariectomy-induced bone loss in Mice. Biomed. Pharmacother. 2017, 88, 804-813.

(39) Sashidhara, K. V.; Kumar, M.; Khedgikar, V.; Kushwaha, P.; Modukuri, R. K.; Kumar, A.; Gautam, J.; Singh, D.; Sridhar, B.; Trivedi, R. Discovery of coumarin- dihydropyridine hybrids as bone anabolic agents. J. Med. Chem. 2013, 56, 109-122.

(40) Sharma, A.; Chakravarti, B.; Gupt, M. P.; Siddiqui, J. A.; Konwar, R.; Tripathi, R. P. Synthesis and anti breast cancer activity of biphenyl based chalcones. Bioorg. Med. Chem. 2010, 18, 4711-4720.

(41) Khedgikar, V.; Ahmad, N.; Kushwaha, P.; Gautam, J.; Nagar, G. K.; Singh, D.; Trivedi, P. K.; Mishra, P. R.; Sangwan, N. S.; Trivedi, R. Preventive effects of withaferin an isolated from the leaves of an Indian medicinal plant withania somnifera (1.): comparisons with17-betaestradiol and alendronate. Nutrition 2015, 31, 205-213.

(42) Plimpton, S. Fast parallel algorithms for short-range molecular dynamics. J. Comput. Phys. 1995, 117, 1-19.

(43) Van Duin, A. C. T.; Dasgupta, S.; Lorant, F.; Goddard, W. A. ReaxFF: a Reactive force field for hydrocarbons. J. Phys. Chem. A 2001, 105, 9396-9409.

(44) Weismiller, M. R.; Van Duin, A. C. T.; Lee, J.; Yetter, R. A. ReaxFF reactive force field development and applications for molecular dynamics simulations of ammonia borane dehydrogenation and combustion. J. Phys. Chem. A 2010, 114, 5485-5492.

(45) Ertug, B. Powder preparation, properties and industrial applications of hexagonal boron nitride. In Sintering Applications. Ertug, B., Ed.; In Tech: Rijeka, 2013; Chapter 2, pp 33-55. 